Review

\title{
Selenium Biochemistry and Bioavailability: Implications for Animal Agriculture
}

\author{
Shaniko Shini ${ }^{1, *}$, Asad Sultan ${ }^{2}$ and Wayne L. Bryden ${ }^{3}$ \\ 1 School of Biomedical Sciences, University of Queensland, St Lucia, QLD 4072, Australia \\ 2 Department of Poultry Science, Khyber Pakhtunkhwa Agricultural University, Peshawar 25120, \\ Pakistan; E-Mail: asadzia2003@yahoo.com \\ 3 School of Agriculture and Food Sciences, University of Queensland, Gatton, QLD 4343, Australia; \\ E-Mail: w.bryden@uq.edu.au
}

* Author to whom correspondence should be addressed; E-Mail: s.shini@uq.edu.au.

Academic Editor: Les Copeland

Received: 20 September 2015 / Accepted: 10 December 2015 / Published: 14 December 2015

\begin{abstract}
Selenium (Se) is an essential trace mineral required for growth, development, immune function, and metabolism. Selenium exerts its biological effects as an integral component of selenoproteins (SePs). Deficiency or low Se status leads to marked changes in many biochemical pathways and a range of pathologies and disorders which are associated with SeP function. Animals, and presumably humans, are able to efficiently utilize nutritionally adequate levels of Se in both organic and inorganic forms. It is now clear that the bioavailability of Se varies depending on the source and chemical form of the Se supplement. There are a range of products available for dietary Se supplementation, however, organic sources have been shown to be assimilated more efficiently than inorganic compounds and are considered to be less toxic and more appropriate as a feed supplement. Yeast enriched with Selenohomoalanthionine (SeHLan) has recently become commercially available, and initial research suggests that it may be an efficacious source for the production of Se enriched animal products.
\end{abstract}

Keywords: selenium; selenoproteins; biochemistry; bioavailability; deficiency; excess; requirements; supplements; organic compounds 


\section{Introduction}

Selenium (Se) is an essential trace element for animals and humans. It was discovered in 1818 and named Selene after the Greek goddess of the moon. However, it was not until the 1950s that it was recognized as an essential dietary micronutrient for mammals [1]. Selenium presents a nutritional conundrum because it is an essential trace element with a narrow range between dietary adequacy and toxicity. It is this characteristic of Se that allows it to be considered as either a friend, or, a foe.

Selenium exerts its biological effects as an integral component of selenoproteins (SePs) that contain selenocysteine at their active site [2]. Some thirty SePs, mostly enzymes, have been identified, including a series of glutathione peroxidases, thioredoxin reductases, and iodothyronine deiodinases [1-4]. The majority play important roles in redox regulation, detoxification, immunity and viral suppression [5-7]. Deficiency or low Se status leads to marked changes in many biochemical pathways and a range of pathologies associated with defects of SeP function may occur [8-10].

Selenium content of soils can vary widely. In areas where soils are low in bioavailable Se, deficiencies can occur in humans and animals consuming plant based foods grown in those soils. Selenium deficiency have been reported in many countries including China, Japan, Korea, and Siberia, Northern Europe, USA, Canada, New Zealand, and Australia [11-13]. Within each country there are large regional differences in soil Se status and in some localities there are plants that accumulate Se resulting in Se toxicity (or selenosis) in grazing animals. However, health outcomes are not only dependent on the total Se content of soils, but also on the amount of Se taken up into plants and animals - the bioavailable selenium [11].

Dietary Se supplementation was first permitted some forty years ago [13]. Since then, there have been significant advances in our knowledge of Se metabolism and the important role that Se plays in animal productivity and health $[3,6,9]$. During this period, Se has become an important addition to dietary supplements for animals [14]. The following pages provide an overview of the nutritional biochemistry of Se, and an update on recent developments in Se bioavailability and the possible impact on Se enrichment of animal products.

\section{Biochemistry of Selenium and Selenoproteins}

Selenium exists in four oxidation states: elemental $\mathrm{Se}\left(\mathrm{Se}^{0}\right)$, selenide $\left(\mathrm{Se}^{-2}\right)$, selenite $\left(\mathrm{Se}^{+4}\right)$, and selenate $\left(\mathrm{Se}^{+6}\right)$ in a variety of inorganic and organic matrices [14]. The natural soluble inorganic forms, selenite and selenate, account for the majority of total global selenium [12]. The ultimate source of all $\mathrm{Se}$ is the rocks and soils of our terrestrial environment. Most soils contain from 0.1 to $2 \mu \mathrm{g} / \mathrm{g}$ of Se, but this is not evenly distributed. Some areas of the world have soils rich in Se $(100 \mu \mathrm{g} / \mathrm{g})$, while many areas have deficient soils (none or $>0.1 \mu \mathrm{g} / \mathrm{g}$ ) [11]. Organically bound selenide compounds are predominantly seleno-amino acids; the principle chemical form of $\mathrm{Se}$ in animal tissues is selenocysteine, while selenomethionine predominates in plants [15].

The chemistry of selenium resembles that of sulphur in several respects but these elements are not completely interchangeable in animal systems. Both, sulphur and Se occur in proteins as constituents of amino acids. Sulphur is one of the most prevalent elements in the body and is present in the sulphur-containing amino acids: methionine, cysteine, homocysteine and taurine. Selenium is a trace 
element and a component of the amino acids selenocysteine, and selenomethionine [2]. Selenocysteine is identical to cysteine except that sulphur is replaced by a Se atom, which is typically ionized at physiological $\mathrm{pH}$ when compared with sulphur-containing species.

Selenocysteine (from animal tissues) and selenomethionine (from plants, marine algae, yeast and bacteria) are both sources of Se suitable for synthesis of SePs [16]. Selenocysteine is incorporated into selenium-containing proteins, designated selenoproteins, following the action of a specific codon for selenocysteine residue [3]. Replacement of selenocysteine by cysteine in a SeP usually results in a dramatic decrease of enzymatic activity, confirming that the ionized Se atom is critical for optimum protein function [9]. Significantly, within all cell types there is a specific biosynthesis pathway that facilitates selenocysteine synthesis and its subsequent incorporation into SePs. Cellular Se concentrations are therefore tightly regulated. The regulation of SeP synthesis is central to understanding Se homeostasis and disorders following the failure of homeostasis [5,17,18]. Cellular Se concentration is a key regulator of Se incorporation into SePs and acts mainly at the post-transcriptional level in response to alterations in Se availability [19]. Selenocysteine biosynthesis represents the main regulatory point for SeP synthesis and not absorption as occurs with many nutrients. In contrast, ingested selenomethionine can be nonspecifically incorporated into proteins in place of methionine or converted to selenocysteine by the trans-sulphuration pathway in liver or kidney and may be used as a biological Se pool $[6,17]$.

The biochemistry of Se is different from most other trace elements as it is incorporated in proteins (SePs) at their highest level of complexity and function. Selenoproteins incorporate selenium only in the form of selenocysteine and this occurs during translation in the ribosome using a transfer RNA specific for selenocysteine. Seleno-amino acids (selenocysteine or selenocystine and selenomethionine) are required for the synthesis of selenium-containing peptides and proteins [15]. There are no known human or animal functionally active SePs that contain selenomethionine.

Only proteins that are genetically programmed and perform essential biological functions are classified as SePs [3]. Some of these SePs are enzymes such as the six antioxidant glutathione peroxidases and the three thioredoxin reductases; the three deiodinases are involved in thyroid function by catalyzing the activation and deactivation of the thyroid hormones. [20]. Selenoprotein P, for example, functions as a transporter of selenium between the liver and other organs [4]. The functional characterization of many SePs remains to be delineated.

\section{Selenium Absorption, Distribution and Metabolic Fate}

An overview of the metabolism of Se is shown in Figure 1. Absorption of selenium occurs in the small intestine, where both inorganic and organic forms of Se are readily absorbed. Selenite is passively absorbed across the gut wall, while selenate appears to be transported by a sodium-mediated carrier mechanism shared with sulphur [14,21]. Organic forms of Se are actively transported. Selenium is distributed throughout the body from the liver to the brain, pancreas and kidneys. The highest Se concentrations are found in the liver and kidneys but the greatest total concentration occurs in muscle because of their proportion of body weight [22]. However, dose-response studies conducted with chicken and lamb have found that in muscle tissue, the proportion of selenomethionine and selenocysteine was equivalent [23], suggesting that both selenomethionine and selenocysteine- 
containing proteins are able to be absorbed and transferred to peripheral tissues. However, the mechanism is unclear. Selenium is transported in blood by two SePs; selenoprotein P (SePP1) and extracellular glutathione peroxidase (GSH-Px) [6]. Plasma SePP1 contains more than 50\% of circulating Se [6,19]. Only insignificant transitory amounts of free selenomethionine are found in blood. It has also been shown, that dietary supplementation with Se enriched yeast increased blood selenomethionine in a dose dependent manner whereas selenocysteine remained constant [24]. These changes in circulating selenised amino acids may reflect saturation of selenoenzymes and a shift from incorporation of Se into functional SePs to non-specific incorporation of selenomethionine into liver tissue protein. This may indicate that alternative transport mechanisms for selenomethionine exist and need to be clarified through further research. Following protein turnover, the released Se, can be recycled via enterohepatic circulation or excreted. Selenium is eliminated primarily in urine and faeces [17]. The distribution between the two routes varies with the level of exposure and time after exposure.

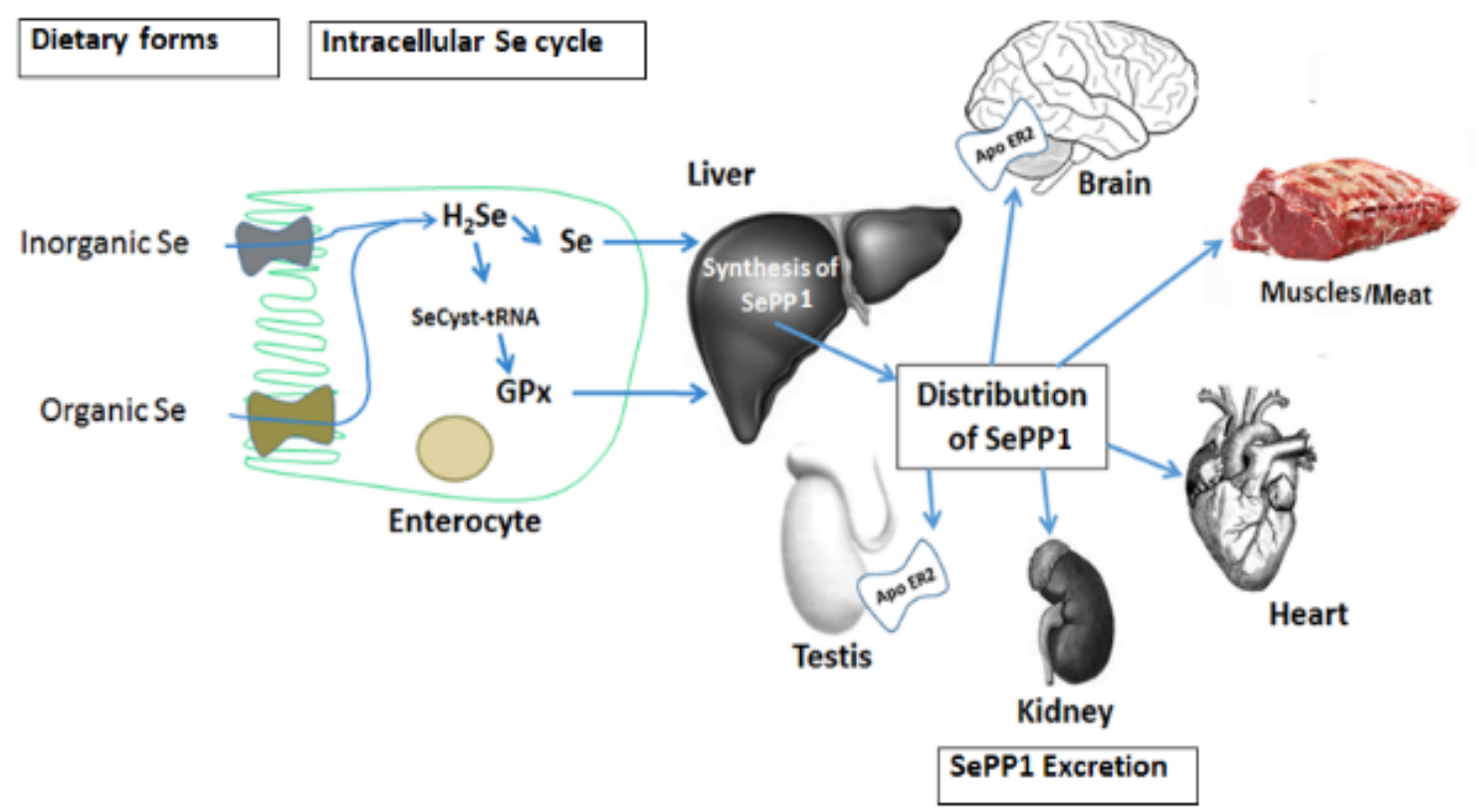

Figure 1. General pathways of Se absorption, hepatic synthesis of SePP1 and distribution to various organs. Adapted from Kumar and Priyadarsini [25].

In ruminants, selenite is the primary compound available for absorption because the reducing conditions within the rumen convert the majority of selenate to selenite [26]. In the rumen, about a third of selenite is converted to insoluble forms that are passed into manure. Of the soluble selenite that reaches the intestine, some $40 \%$ will be absorbed, compared to about $80 \%$ of selenomethionine [27]. Subsequently, in ruminants, the digestibility of Se from selenite is around $50 \%$ compared to about $66 \%$ for selenium-yeast [27]. There is no information on the impact of the gut microbiota on the Se requirements of monogastric animals.

Inorganic Se is recognized by the digestive tissues and is absorbed and converted into SePs [27]. In contrast, organic Se (selenomethionine) is not recognized as Se-containing by mammalian cells [28]. Hence, selenomethionine is absorbed and metabolized relative to methionine needs. If selenomethionine is broken down within the cell, Se is released and recognized by the cell as a mineral [29]. It is then processed according to the need for Se. However, if the cell does not break down selenomethionine, it 
may be inadvertently incorporated into a wide variety of proteins that are not genetically programmed to contain Se [30], rather than be excreted rapidly. Such incorrect incorporation of Se into protein may be toxic [3,31]. As a metabolic safeguard, neither dietary selenocysteine nor selenomethionine is directly incorporated into selenoproteins. All dietary forms of selenium must be metabolized and converted to selenocysteine and selenoproteins under the genetically controlled mechanism within the cell [32]. Much of the absorbed organic Se is transferred into the amino acid pool, where together with the existing intracellular pool it is metabolized by different pathways (Figure 1). From there, it is enzymatically converted in the liver to selenide, which serves as the Se source for selenocysteine synthesis [33].

\section{Selenium Deficiency and Requirements}

Selenium acts biochemically in mammals and birds in a complimentary manner to vitamin E [34-36]. Both nutrients prevent peroxidation of unsaturated fatty acids in cell membranes. Most of the deficiency signs of these nutrients can be explained by their antioxidant properties. The requirement for each is therefore influenced by the dietary concentration of the other [2,37]. For example, the Se requirement of the chick is inversely proportional to dietary vitamin E intake. Thus Se has sparing effect on the requirement for vitamin E and vice versa; Se-dependent peroxidases essentially serve as antioxidants when vitamin E levels are not sufficient to prevent lipid peroxidation. On the other hand, vitamin E neutralizes oxidants before the initiation of chain reactions thus reducing Se loss from the body [16]. The metabolic interrelationship of GSH-Px with vitamin E is particularly evident in deficiency diseases that can be prevented either by vitamin E or Se [1,37]. The other major role for Se is the production of thyroid hormones as a component of the enzyme type 1 iodothyronine deiodinase which converts triiodothyronine to thyroxine [1].

Manifestation of Se deficiency can take many forms and varies between species. Muscular degeneration or white muscle disease occurs to varying degrees in all species [14,38]. In birds, pancreatic fibrosis is an uncomplicated Se deficiency, whereas exudative diathesis (generalised oedema visible under the skin) is responsive to both Se and vitamin E [34]. Pigs with hepatosis diatetica (severe necrotic liver lesions) are responsive to Se supplements [39], while both Se and vitamin E are effective in treating mulberry heart disease (a dietetic microangiopathy) [40]. Reproductive disorders, including retained placenta in dairy cows [41], while lowered disease resistance are observed in all Se deficient species [26,27]. Some species, such as rabbits and horses, seem to be more dependent on vitamin $\mathrm{E}$ than Se for their antioxidant protection [42]. This may reflect species differences in dependence on nonselenium containing GSH-Px.

Selenium presents a nutritional conundrum because it is both essential and highly toxic. Adequate Se intake levels have a relatively narrow range between deficiency and toxicity. Dietary Se levels of $0.2-0.3 \mathrm{mg} \mathrm{Se} / \mathrm{kg}$ diet have shown to prevent deficiency and resultant diseases such as white muscle disease in cattle and sheep, exertional myopathy in horses, hepatosis dietetica in pigs, and exudative diathesis in chickens [22,37]. The tolerable concentrations for Se in most livestock feed is considered to be 2-5 mg Se/kg diet, although some believe $4-5 \mathrm{mg} \mathrm{Se} / \mathrm{kg}$ diet can inhibit growth. Animals that consume diets containing 5-40 mg Se/kg diet over a period of several weeks or months suffer from chronic selenosis [37]. 
There are several approaches to measuring Se status. These include the measurement of changes in plasma Se concentration, measurement of GSH-Px enzyme activity, and absorption/retention studies. The use of stable isotopes of Se has been used in human studies and to determine endogenous forms of selenium in foods [43]. All of these biomarkers are useful indicators of Se status but because of the role of Se in many biochemical pathways, a single indicator may not be an appropriate index of Se status.

\section{Dietary Selenium Supplementation}

Soils are the major source of Se for plants, while plants are major sources of Se for animals. To improve Se status of plants grown on deficient soils, Se enriched fertilizers may be used or plant breeding strategies may be applied [13]. Despite these strategies, Se is also routinely added to animal diets to ensure that requirements are met. There has been increased interest recently in dietary supplementation with Se to enrich animal products. The production of selenium-enriched meat, milk and eggs is viewed as an effective and safe way of improving the selenium status of humans [44].

There are a range of products available for dietary Se supplementation (Table 1). Selenium is commonly added to diets as sodium selenite. However, there has been growing interest in dietary addition of organic Se. Organic sources are assimilated more efficiently than inorganic Se and considered to be less toxic and therefore more appropriate as a feed supplement $[22,45]$. Yeast has become the most popular vehicle for the addition of organic Se because of its rapid growth, ease of culture and high capacity to accumulate Se [46-48]. The major product in selenized yeast is selenomethionine.

Selenomethionine was found to be four times more effective than selenite in preventing the characteristic pancreatic degeneration caused by selenium deficiency in chicks [49]. Selenium yeast (selenomethionine) was found to be much more effective than inorganic Se in increasing the Se concentration of cow's milk [31]. This is in accord with many animal studies and human clinical trials that have demonstrated the superior efficacy of L-selenomethionine, in increasing Se muscle content compared to inorganic Se $[45,50]$.

Table 1. Selenium compounds and their application in animal and human nutrition.

\begin{tabular}{|c|c|c|c|}
\hline Name and Content & Nature or Origin & Uses & Reference * \\
\hline $\begin{array}{c}\text { Sodium selenate } \\
\text { Sodium selenite } \\
\text { Selenase } 50 \mathrm{mcg} / \mathrm{mL}\end{array}$ & Synthetic Inorganic & $\begin{array}{l}\text { For short-term selenium } \\
\text { supplementation; orally in the } \\
\text { diet, or by injections for both } \\
\text { animals and humans }\end{array}$ & $\begin{array}{c}{[12,36,44} \\
45,49,50]\end{array}$ \\
\hline Sintomin BIOSEL 2000 & $\begin{array}{c}\text { Inactive dry yeast } \\
\text { containing high levels of } \\
\text { organic selenium }\end{array}$ & All animals & [51] \\
\hline
\end{tabular}


Table 1. Cont.

\begin{tabular}{|c|c|c|c|}
\hline Name and Content & Nature or Origin & Uses & Reference * \\
\hline $\begin{array}{l}\text { Selyeast Selenomethionine: } \\
1000,2000,3000\end{array}$ & $\begin{array}{l}\text { Yeast rich in organic } \\
\text { selenium }\end{array}$ & For use as animal feed. & $\begin{array}{c}{[22,44,45} \\
47,48]\end{array}$ \\
\hline $\begin{array}{l}\text { Selemax }^{\circledR}(1000,2000) \\
70 \% \text { of total selenium in the } \\
\text { form of seleno-methionine }\end{array}$ & $\begin{array}{c}\text { Inactive dry yeast } \\
\text { containing organic selenium }\end{array}$ & All animal species and categories & {$[22,45,52]$} \\
\hline $\begin{array}{c}\text { SeLECT } \\
\mathrm{L}(+) \text { Selenomethionine \& } \\
\text { Vitamin E }\end{array}$ & $\begin{array}{c}\text { Organic, pure } \\
\text { selenomethionine }\end{array}$ & $\begin{array}{l}\text { Oral administration humans } \\
\text { (capsules), and animals }\end{array}$ & $\begin{array}{l}{[22,44,} \\
45,49]\end{array}$ \\
\hline $\begin{array}{l}\text { Sel Plex } \mathrm{TM}>50 \% \text { of total } \\
\text { selenium in the form of } \\
\text { seleno-methionine }\end{array}$ & $\begin{array}{c}\text { Yeast rich in } \\
\text { organic selenium }\end{array}$ & All animals & $\begin{array}{l}{[22-24,44} \\
45,50,51]\end{array}$ \\
\hline $\begin{array}{c}\text { BiOnyc }^{\circledR} \text { Tor-Sel } \\
\text { Selenohomolanthionine } \\
\text { (SeHLan) }\end{array}$ & $\begin{array}{l}\text { Yeast rich in organic } \\
\text { selenium }\end{array}$ & All animals and humans & {$[53,54]$} \\
\hline $\begin{array}{c}\text { L-Selenomethionine } \\
\text { 100\% L-selenomethionine }\end{array}$ & $\begin{array}{c}\text { Naturally occurring } \\
\text { organoselenium compound } \\
\text { made by plants }\end{array}$ & $\begin{array}{l}\text { Predominate form of selenium } \\
\text { supplement in food for humans; } \\
\text { some use in animals }\end{array}$ & $\begin{array}{l}{[22,44,} \\
45,53]\end{array}$ \\
\hline $\begin{array}{c}\text { SeMC тм } \\
\text { Methylselenocysteine 98\% }\end{array}$ & $\begin{array}{c}\text { Naturally occurring } \\
\text { organoselenium compound } \\
\text { made by plants }\end{array}$ & Humans & {$[22,53,55]$} \\
\hline
\end{tabular}

* Source: generated from references and product information sheets.

Selenohomolanthionine (SeHLan; 2 hydroxy-4-methylselenobutanoic acid) was recently identified in Japanese pungent radish and has generated much interest as it was less toxic in human cell culture than selenomethionine [53,56]. As shown in Figure 2, differences in metabolism between SeHLan and selenomethionine may, in-part, explain the apparent difference in toxicity. Selenomethionine mimics methionine by sharing the same metabolic pathways and can replace methionine in peptide synthesis, and as noted above, thus causing signs of selenosis [31]. The proposed metabolic pathway for SeHLan (Figure 2) appears to be much less complex; SeHLan is only utilized in the trans-selenation pathway for selenoprotein synthesis and therefore is not expected to interfere with the methionine metabolic pathways. The tissue distribution of these two selenoamino acids may also contribute to differences in toxicity [6]. Both are distributed throughout the body with higher liver and pancreas accumulation of selenomethionine in contrast to SeHLan which preferentially accumulates in the liver and kidneys [19]. At higher doses, selenomethionine has been shown to induce pancreas damage $[55,57]$ whereas SeHLan is excreted by the kidneys without inducing pancreatic damage [53]. Tsuji et al., have reported specific toxicity of SeHLan to the kidneys which could be avoided when it is administered at a lower dose than in their study [53]. 


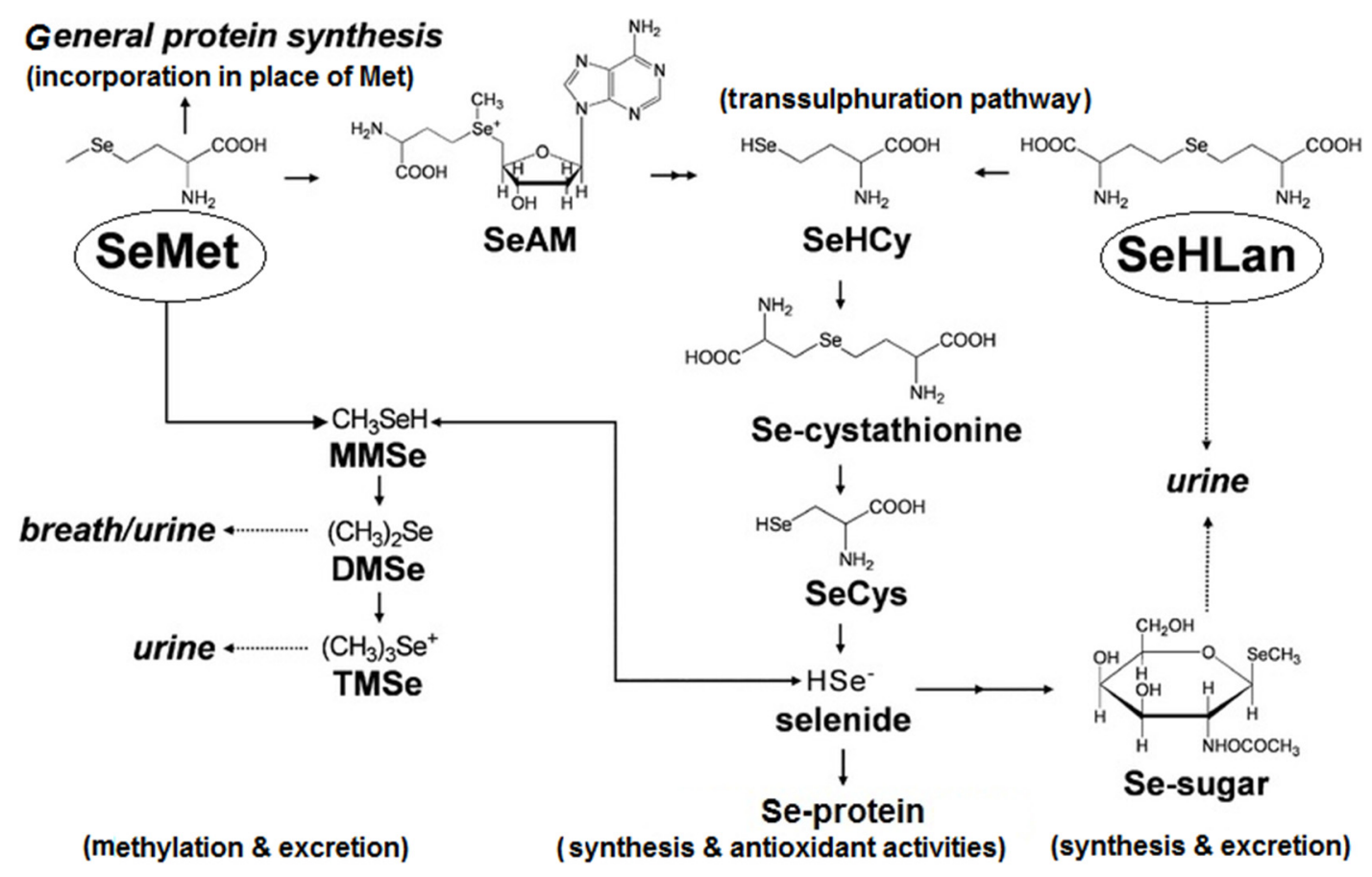

Figure 2. Proposed metabolic pathways for SeHLan and SeMet in animal cells. Adapted from Tsuji et al. 2010 [53].

Selenomethionine enriched yeast has been used as a feed supplement in animal agriculture for many years. Recently, a yeast product enriched with SeHLan has become available and efficacy studies with growing pigs [58] and broiler chickens [54] have been conducted with these selenoamino acid sources. In the studies both selenomethionine (Sel Plex) and SeHLan (AB Tor-Sel) were compared to sodium selenite. In clean research, experimental conditions, as demonstrated on many occasions, dietary supplementation with both inorganic and organic selenium resulted in similar animal and bird performance. However, tissue accumulation was significantly greater when the organic forms of Se were fed, which is in accord with the literature [31,48-50]. Interestingly, the yeast enriched with SeHLan generated significantly higher Se concentrations in muscle tissue of broiler chickens than the selenomethionine enriched product [54]. The implication of this finding in both pig and broilers may imply a greater efficacy of SeHLan in stressful commercial environments. These interesting results should be the subject of further research.

\section{Conclusions}

Selenium's nutritional essentiality was discovered in the 1950s. It is now clear that the importance of having adequate amounts of $\mathrm{Se}$ in the diet is primarily due to the fact that this micronutrient is required for the biosynthesis of selenocysteine as a part of functional selenoproteins. Improved analytical techniques will be required to answer those questions that still remain regarding Se metabolism. Although animals, and presumably humans, are able to efficiently utilize nutritionally adequate levels of Se in both organic and inorganic forms for SeP synthesis, it is clear that the bioavailability of Se varies, depending on the source and chemical form of the Se supplement. Tissue enrichment with Se is 
greater when organic forms of the micronutrient are fed. Greater tissue reserves of Se may enhance an animal's resilience to stress and disease challenge.

Organic Se, in the form of yeast enriched with selenomethionine, is widely used in animal nutrition. Recently, yeast enriched with SeHLan became commercially available and initial research suggests that it may also be an efficacious source for tissue accumulation of Se. This has obvious implications for the production of Se enriched animal products.

\section{Conflicts of Interest}

The author declares no conflict of interest.

\section{References}

1. Brown, K.M.; Arthur, J.R. Selenium, selenoproteins and human health: A review. Public Health Nutr. 2001, 4, 593-599.

2. Bock, A.; Forchhammer, K.; Heider, J.; Leinfelder, W.; Sawers, G.; Veprek, B.; Zinoni, F. Selenocysteine: The 21st amino acid. Mol. Microbiol. 1991, 5, 515-520.

3. Hatfield, D.L.; Gladyshev, V.N. How Selenium Has Altered Our Understanding of the Genetic Code. Mol. Cell. Biol. 2002, 22, 3565-3576.

4. Reeves, M.A.; Hoffmann, P.R. The human selenoproteome: Recent insights into functions and regulation. Cell. Mol. Life Sci. 2009, 66, 2457-2478.

5. Bellinger, F.P.; Raman, A.V; Reeves, M.A.; Berry, M.J. Regulation and function of selenoproteins in human disease. Biochem. J. 2009, 422, 11-22.

6. Burk, R.F.; Hill, K.E.; Motley, A.K. Selenoprotein metabolism and function: Evidence for more than one function for selenoprotein P. J. Nutr. 2003, 133, 1517s-1520s.

7. Duntas, L.H. The role of selenium in thyroid autoimmunity and cancer. Thyroid 2006, 16, 455-460.

8. Cardoso, B.R.; Roberts, B.R.; Bush, A.I.; Hare, D.J. Selenium, selenoproteins and neurodegenerative diseases. Metallomics 2015, 7, 1213-1228.

9. Moghadaszadeh, B.; Beggs, A.H. Selenoproteins and their impact on human health through diverse physiological pathways. Physiology 2006, 21, 307-315.

10. Köhrle, J.; Jakob, F.; Contempré, B.; Dumont, J.E. Selenium, the thyroid, and the endocrine system. Endocr. Rev. 2005, 26, 944-984.

11. Selinus, O.; Fordyce, F. Selenium deficiency and toxicity in the environment. In Essentials of Medical Geology; Springer Netherlands: Heidelberg, Germany, 2013; pp. 375-416.

12. Oldfield, J.E. Selenium World Atlas: Updated Edition; Selenium-Tellurium Development Association: Grimbergen, Belgium, 2002.

13. WHO. Guidelines on Food Fortification with Micronutrients; World Health Organization: Geneva, Switzerland, 2006.

14. Reilly, C. Selenium in Food and Health; Springer Science Media: New York, NY, USA, 2006.

15. Mangiapane, E.; Pessione, A.; Pessione, E. Selenium and selenoproteins: An overview on different biological systems. Curr. Protein Pept. Sci. 2014, 15, 598-607.

16. Rahmanto, A.S.; Davies, M.J. Selenium-containing amino acids as direct and indirect antioxidants. IUBMB Life 2012, 64, 863-871. 
17. Patching, S.G.; Gardiner, P.H. Recent developments in selenium metabolism and chemical speciation: A review. J. Trace Elem. Med. Biol. 1999, 13, 193-214.

18. Steinbrenner, H.; Sies, H. Selenium homeostasis and antioxidant selenoproteins in brain: Implications for disorders in the central nervous system. Arch. Biochem. Biophys. 2013, 536, 152-157.

19. Hill, K.E.; Wu, S.; Motley, A.K.; Stevenson, T.D.; Winfrey, V.P.; Capecchi, M.R.; Atkins, J.F.; Burk, R.F. Production of selenoprotein P (Sepp1) by hepatocytes is central to selenium homeostasis. J. Biol. Chem. 2012, 287, 40414-40424.

20. Labunskyy, V.M.; Hatfield, D.L.; Gladyshev, V.N. Selenoproteins: Molecular pathways and physiological roles. Physiol. Rev. 2014, 94, 739-777.

21. Wastney, M.E.; Combs Jr, G.F.; Canfield, W.K.; Taylor, P.R.; Patterson, K.Y.; Hill, A.D.; Moler, J.E.; Patterson, B.H. A human model of selenium that integrates metabolism from selenite and selenomethionine. J. Nutr. 2011, 141, 708-717.

22. Schrauzer, G.N. Nutritional selenium supplements: Product types, quality, and safety. J. Am. Coll. Nutr. 2001, 20, 1-4.

23. Bierla, K.; Dernovics, M.; Vacchina, V.; Szpunar, J.; Bertin, G.; Lobinski, R. Determination of selenocysteine and selenomethionine in edible animal tissues by $2 \mathrm{D}$ size-exclusion reversed-phase HPLC-ICP MS following carbamidomethylation and proteolytic extraction. Anal. Bioanal. Chem. 2008, 390, 1789-1798.

24. Juniper, D.T.; Phipps, R.H.; Bertin, G. Effect of dietary supplementation with selenium-enriched yeast or sodium selenite on selenium tissue distribution and meat quality in commercial-line turkeys. Animal 2011, 11, 1751-1760.

25. Santhosh Kumar, B.; Priyadarsini, K.I. Selenium nutrition: How important is it? Biomed. Prev. Nutr. 2014, 4, 333-341.

26. Spears, J.W. Trace Mineral Bioavailability in Ruminants. J. Nutr. 2003, 133, 1506S-1509S.

27. Weiss, W.P. Selenium sources for dairy cattle. In Proceedings of Tri-State Dairy Nutrition Conference, Fort Wayne, IN, USA, May 2005; pp. 61-72.

28. Behne, D.; Kyriakopoulos, A. Mammalian selenium-containing proteins. Ann. Rev. Nutr. 2001, 21, 453-473.

29. López-Alonso, M.R. Trace Minerals and Livestock: Not Too Much Not Too Little. ISRN Vet. Sci. 2012, doi:10.5402/2012/704825.

30. Combs, G.F. Biomarkers of Selenium Status. Nutrients 2015, 7, 2209-2236.

31. Rayman, M.P. The use of high-selenium yeast to raise selenium status: how does it measure up? Br. J. Nutr. 2004, 92, 557-573.

32. Turanov, A.A.; Xu, X.-M.; Carlson, B.A.; Yoo, M.-H.; Gladyshev, V.N.; Hatfield, D.L. Biosynthesis of Selenocysteine, the 21st Amino Acid in the Genetic Code, and a Novel Pathway for Cysteine Biosynthesis. Adv. Nutr.: An Int. Rev. J. 2011, 2, 122-128.

33. Ma, S.; Caprioli, R.M.; Hill, K.E.; Burk, R.F. Loss of selenium from selenoproteins: Conversion of selenocysteine to dehydroalanine in vitro. J. Am. Soc. Mass. Spectrom. 2003, 14, 593-600.

34. Combs, G.F.; Scott Jr., M.L. Dietary requirements for vitamin E and selenium measured at the cellular level in the chick. J. Nutr. 1974, 104, 1292-1296. 
35. Scott, M.L.; Noguchi, T.; Combs, Jr., G.F. New evidence concerning mechanisms of action of vitamin E and selenium. Vitam. Horm. 1974, 32, 429-444.

36. Diplock, A.T. The nutritional and metabollic roles of selenium and vitamin E. Proc. Nutr. Soc. 1974, 33, 315-322.

37. National Research Council (US) Subcommittee on Selenium. Selenium in Nutrition: Revised Edition; National Academies Press: Washington, DC, USA, 1983.

38. Kinoshita, H.; Sugai, K.; Goto, Y.; Nonaka, I. Early onset distal muscular dystrophy. Brain Dev. 1995, 17, 206-209.

39. Sharp, B.A.; Van Dreumel, A.A.; Young, L.G. Vitamin E, selenium and methionine supplementation of dystrophogenic diets for pigs. Can. J. Comp. Med. 1972, 36, 398-402.

40. Sharp, B.A.; Young, L.G.; Van Dreumel, A.A. Dietary induction of mulberry heart disease and hepatosis dietetica in pigs. I. Nutritional aspects. Can. J. Comp. Med. 1972, 36, 371-376.

41. Jovanović, I.B.; Veličković, M.; Vuković, D.; Milanović, S.; Valčić, O.; Gvozdić, D. Effects of Different Amounts of Supplemental Selenium and Vitamin E on the Incidence of Retained Placenta, Selenium, Malondialdehyde, and Thyronines Status in Cows Treated with Prostaglandin F2 $\alpha$; for the Induction of Parturition. J. Vet. Med. 2013, doi:10.1155/2013/867453.

42. Cheeke, P.R.; Dierenfeld, E.S. Comparative animal nutrition and metabolism; CABI: Wallingford, UK, 2010.

43. Finley, J.W. Bioavailability of selenium from foods. Nutr. Rev. 2006, 64, 146-151.

44. Fisinin, V.I.; Papazyan, T.T.; Surai, P.F. Producing selenium-enriched eggs and meat to improve the selenium status of the general population. Crit. Rev. Biotechnol. 2009, 29, 18-28.

45. Schrauzer, G.N.; Surai, P.F. Selenium in human and animal nutrition: resolved and unresolved issues. A partly historical treatise in commemoration of the fiftieth anniversary of the discovery of the biological essentiality of selenium, dedicated to the memory of Klaus Schwarz (1914-1978) on the occasion of the thirtieth anniversary of his death. Crit. Rev. Biotechnol. 2009, 29, $2-9$.

46. Kieliszek, M.; Błażejak, S.; Gientka, I.; Bzducha-Wróbel, A. Accumulation and metabolism of selenium by yeast cells. Appl. Microbiol. Biotechnol. 2015, 99, 5373-5382.

47. Suhajda, A.; Hegoczki, J.; Janzso, B.; Pais, I.; Vereczkey, G. Preparation of selenium yeasts I. Preparation of selenium-enriched Saccharomyces cerevisiae. J. Trace Elem. Med. Biol. 2000, 14, 43-47.

48. Ouerdane, L.; and Mester, Z. Production and characterization of fully selenomethionine-labeled Saccharomyces cerevisiae. J. Agric. Food Chem. 2008, 56, 11792-11799.

49. Cantor, A.H.; Langevin, M.L.; Noguchi, T.; Scott, M.L. Efficacy of selenium in selenium compounds and feedstuffs for prevention of pancreatic fibrosis in chicks. J. Nutr. 1975, 105, 106-111.

50. Payne, R.L.; Southern, L.L. Comparison of inorganic and organic selenium sources for broilers. Poult. Sci. 2005, 84, 898-902.

51. da Silva, ICM; Ribeiro, A.M.L.; Canal, C.W.; Trevizan, L.; Macagnan, M.; Gonçalves, T.A.; Hlavac, N.R.C.; de Almeida, L.L.; Pereira, R.A. The impact of organic and inorganic selenium on the immune system of growing broilers submitted to immune stimulation and heat stress. Rev. Bras. Cienc. Avic. 2010, 12, 247-254 
52. Oliveira, T.F.B.; Rivera, D.F.R.; Mesquita, F.R.; Braga, H.; Ramos, E.M.; Bertechini A.G. Effect of different sources and levels of selenium on performance, meat quality, and tissue characteristics of broilers. J. Appl. Poult. Res. 2014, 23, 15-22.

53. Tsuji, Y.; Mikami, T.; Anan, Y.; Ogra, Y. Comparison of selenohomolanthionine and selenomethionine in terms of selenium distribution and toxicity in rats by bolus administration. Metallomics 2010, 2, 412-418.

54. Celi, P.; Selle, P.H.; Cowieson, A.J. Effects of organic selenium supplementation on growth performance, nutrient utilisation, oxidative stress and selenium tissue concentrations in broiler chickens. Anim. Prod. Sci. 2014, 54, 966-971.

55. Suzuki, K.T.; Doi, C.; Suzuki, N. Metabolism of 76Se-methylselenocysteine compared with that of 77Se-selenomethionine and 82Se-selenite. Toxicol. Appl. Pharmacol. 2006, 217, 185-95.

56. Anan, Y.; Ogra, Y. Toxicological and pharmacological analysis of selenohomolanthionine in mice. Toxicol. Res. 2013, 2, 115-122.

57. Kaufman, N.; Klavins, J.V.; Kinney, T.D. Pancreatic damage induced by excess methionine. Arch. Pathol. 1960, 70, 331-337.

58. Henman, D.J. (Riverlea Pty Ltd., Corowa, Australia). Personal communication, 2014.

(C) 2015 by the authors; licensee MDPI, Basel, Switzerland. This article is an open access article distributed under the terms and conditions of the Creative Commons Attribution license (http://creativecommons.org/licenses/by/4.0/). 